\title{
BODY MASS INDEX AS A PREDICTOR FOR OBSTRUCTIVE SLEEP APNEA IN SNORING PATIENTS
}

\author{
By \\ Khalid M. Halima' ${ }^{1}$, Safwat A. M. El-Daboosy ${ }^{1}$, Amgad Awad ${ }^{2}$, Saber \\ Abo Al-Hassan ${ }^{3}$ and Mohamed O. Nour ${ }^{4}$ \\ ${ }^{1}$ Department of Chest Diseases, Al Azhar Faculty of Medicine, Egypt \\ ${ }^{2}$ Department of Internal Medicine, Al Azhar Faculty of Medicine, Egypt \\ ${ }^{3}$ Department of Neurology, Assiut Faculty of Medicine, Egypt \\ ${ }^{4}$ Department of Public Health and Community Medicine, Al Azhar Faculty of Medicine, \\ Damietta, Egypt \\ Corresponding author: Khalid M. Halima, \\ Mobile: (+20)01006217783, E-mail: khaledchesthalima@ gmail.com
}

\begin{abstract}
Background: Obstructive sleep apnea (OSA) is a very common disease in the general population that can cause deterioration in the quality of life, chronic diseases, road traffic accidents and excessive mortality in itself. The condition is characterized by repeated episodes of upper airway obstruction, accompanied by nocturnal oxygen desaturation, fragmented sleep and excessive daytime sleepiness.

Objective: To evaluate body mass index (BMI) correlated to apnea-hypopnea index (AHI) and minimum O2 saturation (Nadir $\mathrm{SaO} 2)$.

Patients and Methods: A retrospective database analysis of medical records of One hundred fifty patients with OSA that performed at Almoosa Hospital, Saudi Arabia during the period from August 2016 to August 2019.BMI was calculated for each patient, as well as AHI and Nadir $\mathrm{SaO} 2$ recorded during polysomnography. AHI was used to evaluate the severity of OSA and to assess if there is correlation to BMI values.

Results: The severity of OSA had significant positive correlation with BMI $(\rho=0.13, \mathrm{P}=0.005)$ and significant negative correlation with Nadir $\mathrm{SaO} 2(\rho=-0.27, \mathrm{P}=0.001)$. BMI had significant negative correlation with Nadir $\mathrm{SaO} 2(\rho=-0.18, \mathrm{P}=0.027)$.

Conclusion: Higher BMI values were correlated with lower Nadir $\mathrm{SaO} 2$ during overnight polysomnography. Since hypoxia stress is a risk factor for cardiovascular diseases and alters the lipid metabolism, dietary consulting should be recommended in association with other treatment modalities for OSA.
\end{abstract}

Key words: Body mass index, apnea-hypopnea index, obstructive sleep apnea, Nadir $\mathrm{SaO}$.

\section{INTRODUCTION}

Background: OSA is characterized by repeated episodes of upper airway obstruction, accompanied by nocturnal oxygen desaturation, fragmented sleep and excessive daytime sleepiness (Loberes et al., 2011).

Although its prevalence may vary in different populations and age groups, it has been estimated that OSA affects $24 \%$ 
and $9 \%$ of middle-aged men and women, respectively (Young et al., 2013).

Moreover, the 5-year incidence of sleep disordered breathing in a community-based sample has been found to be $16 \%$ and $7.5 \%$ for mild to moderate and for severe sleep-disordered breathing, respectively (Tishler et al., 2013).

The risk factors most associated with OSA are age, male gender, and high body mass index (BMI). Its prevalence increases with age and is triple in elderly subjects compared to middle-aged individuals. The male/female ratio in middle age is $2-3 / 1$, with a tendency to even out after the menopause (Durán et al., 2010).

OSA and obesity often coexist and interact, sharing multiple pathophysiological mechanisms and consequences. OSA may contribute, at least in part, to some of the pathological processes traditionally ascribed to obesity alone, most notably sympathetic over activity and humoral, metabolic, and neuroendocrine abnormalities (Wolk et al., 2013).

The burden of disease associated with OSA is substantial. OSA is considered a risk factor for hypertension, diabetes mellitus, cardiovascular disease, heart failure, arrhythmias, pulmonary hypertension, and mood disorders (Mannarino et al., 2012).

The gold standard for the diagnosis of OSA is overnight polysomnography (Chung et al., 2013).

However, because polysomnography is expensive and has limited availability with complex technical support, it is essential to know the predictive risk factors for OSA. Based on these predictive risk factors, it is possible to determine which patients should have priority for undergoing polysomnography (Kim et al., 2015).

The aim of the present study was to investigate the effect of BMI on the severity of individual obstruction events.

\section{PATIENTS AND METHODS}

This was a retrospective database analysis of medical records of patients with OSA at Almoosa Hospital, Saudi Arabia, during the period from August 2016 to August 2019.

Patients were tracked across the inpatient and outpatient hospital settings. Ethical approval was obtained from the Institutional Review Board at Almoosa Hospital, Saudi Arabia. Privacy and confidentiality were maintained throughout the study process.

The study population included all patients who visited the hospital during the study period with a chief complaint of snoring as witnessed by a sleep partner, and who underwent overnight polysomnography. The exclusion criteria were patients younger than 14 years of age, those who had previously received or have been receiving treatment for OSA such as continuous positive airway pressure or tonsillectomy and patients with central sleep apnea.

OSA was diagnosed based on AHI $>5$ with witnessed snoring or apnea. The patients were divided into 2 groups according to the presence and absence of apnea. In addition, the severity of sleep apnea was categorized according to AHI into three groups: mild (AHI $>5$ to $\leq 15$ ), 
moderate (AHI $>15$ to $\leq 30$ ), and severe $(\mathrm{AHI}>30)$.

An overnight polysomnography was performed on all patients in the sleep laboratory at Almoosa Specialized Hospital. Electroencephalography, electrooculography, electrocardiography, chin and tibial electromyography, oralnasal airflow meter measured by thermocouples and nasal pressure, oxyhemoglobin saturation measured by finger pulse oximeter, chest and abdominal movements measured by respiratory inductive plethysmography ,body position, and snoring noise captured by a microphone, were recorded. Digital video recording was performed throughout the night. The polysomnographic recordings were analyzed by a certified polysomnographic technologist.

Apnea was defined as cessation of airflow for more than 10 seconds, and hypopnea was defined as a $\geq 50 \%$ decrease in airflow that persisted for more than 10 seconds and was accompanied by oxygen desaturation of $3 \%$ or greater or by arousal (Iber et al., 2017).

AHI was calculated as the total number of respiratory events (apnea plus hypopnea) per hour of sleep. Height and weight were determined on the night of sleep study. Height, in centimeters, was measured with a stadiometer. Weight, in kilograms, was measured with a scale. BMI was calculated as the weight in kilograms divided by the square of the height in meters $(\mathrm{kg} / \mathrm{m} 2) . \mathrm{O} 2$ saturation was measured by pulsi-oximeter.

Statistical analysis of data: Statistical analysis was carried out using the SPSS computer package version 25.0 (IBM SPSS Statistics for Windows, Version 25.0. Armonk, NY: IBM Corp., USA). For descriptive statistics: the mean \pm SD was used for quantitative variables while the frequency and percentage were used for qualitative variables. Chi-square test was used to assess the differences in frequency of qualitative variables while Mann-Whitney test or Kruskal-Wallis test were used to assess the differences in means of quantitative non-parametric variables. Spearman correlation coefficient was used to measure the strength and direction of association between OSA severity (indicated by AHI) and both Nadir $\mathrm{SaO} 2$ and BMI. ROC curve analysis was used to assess the diagnostic ability of different cut-offs of Nadir $\mathrm{SaO} 2$ and BMI for the prediction of OSA that maximizes both sensitivity and specificity. The statistical methods were verified, assuming a significant level of $\mathrm{p}<0.05$. 


\section{RESULTS}

The study included 150 patients who met the inclusion criteria with mean age $52.5 \pm 12.4$ ranged from $14-87$ years. More than half of them (56\%) were males and the mean BMI was $37.6 \pm 8.0$. About $54.7 \%$ had HTN and $39.3 \%$ had DM.
OSA (AHI > 5) was diagnosed in 126 patients (84\%). Significantly, OSA was more detected among males, those with increased age, increased BMI and those with HTN and DM (Table 1).

Table (1): General and clinical characteristics of the studied sample

\begin{tabular}{|c|c|c|c|c|c|}
\hline \multicolumn{2}{|c|}{$\begin{array}{ll}\text { Variables } & \text { Cases } \\
\end{array}$} & $\begin{array}{c}\text { All cases } \\
\mathrm{n}=150(\%)\end{array}$ & $\begin{array}{c}\text { Without OSA } \\
n=24(\%)\end{array}$ & $\begin{array}{c}\text { With OSA } \\
\mathrm{n}=126(\%)\end{array}$ & P-value \\
\hline $\begin{array}{c}\text { Age } \\
\text { (vears) }\end{array}$ & $\begin{array}{l}\text { Mean } \pm \text { SD } \\
\text { Min }- \text { Max }\end{array}$ & $\begin{array}{c}52.5 \pm 12.4 \\
14-87\end{array}$ & $48.4 \pm 13.6$ & $54.8 \pm 12.1$ & 0.021 \\
\hline \multirow{2}{*}{ Gender } & Male & $84(56.0)$ & $9(37.5)$ & $75(59.5)$ & \multirow{2}{*}{0.046} \\
\hline & Female & $66(44.0)$ & $15(62.5)$ & $51(40.5)$ & \\
\hline BMI & $\begin{array}{l}\text { Mean } \pm \text { SD } \\
\text { Min }- \text { Max }\end{array}$ & $\begin{array}{c}37.6 \pm 8.0 \\
21.6-51.1 \\
\end{array}$ & $33.9 \pm 8.2$ & $38.7 \pm 8.4$ & 0.011 \\
\hline \multicolumn{2}{|c|}{ HTN } & $82(54.7)$ & $8(33.3)$ & $74(58.7)$ & 0.022 \\
\hline \multicolumn{2}{|c|}{ DM } & $59(39.3)$ & $5(20.8)$ & $54(42.9)$ & 0.043 \\
\hline \multicolumn{2}{|c|}{ IHD } & $15(10.0)$ & $4(16.7)$ & $11(8.7)$ & 0.235 \\
\hline \multicolumn{2}{|c|}{ Other diseases ${ }^{1}$} & $83(55.3)$ & $17(70.8)$ & $66(52.4)$ & 0.096 \\
\hline
\end{tabular}

BMI: Body mass index, HTN: Hypertension, DM: Diabetes mellitus, IHD: Ischemic heart disease.

1: Some cases had more than one condition.

Values present as number \& \% were analyzed by Chi-square test.

Values present as mean \pm SD were analyzed by Mann-Whitney U test.

Sleep parameters of patients are shown in table 2. The mean sleep efficiency was $73.6 \pm 18.1$. Only $17.3 \%$ had good sleep quality and about one third $(34.7 \%)$ had poor sleep quality with significantly poorer quality among patients with OSA.
The means of Epworth sleepiness score (ESS), arousal index and AHI were significantly higher among patients with OSA (Table 2).

Table (2): Sleep parameters among the studied sample

\begin{tabular}{|c|c|c|c|c|c|}
\hline \multicolumn{2}{|c|}{$\begin{array}{c}\text { Cases } \\
\text { Variables } \\
\end{array}$} & \multirow{2}{*}{$\begin{array}{c}\begin{array}{c}\text { All cases } \\
\mathbf{n}=150(\%)\end{array} \\
73.6 \pm 18.1 \\
10.0-98.2 \\
\end{array}$} & \multirow{2}{*}{$\begin{array}{c}\text { Without OSA } \\
\text { n= 24 (\%) } \\
77.8 \pm 17.7\end{array}$} & \multirow{2}{*}{$\begin{array}{c}\begin{array}{c}\text { With OSA } \\
\mathbf{n}=\mathbf{1 2 6}(\%)\end{array} \\
70.1 \pm 16.6\end{array}$} & \multirow{2}{*}{$\frac{\text { P-value }}{0.041}$} \\
\hline $\begin{array}{c}\text { Sleep } \\
\text { efficiency }\end{array}$ & $\begin{array}{l}\text { Mean } \pm \text { SD } \\
\text { Min }- \text { Max }\end{array}$ & & & & \\
\hline \multirow{3}{*}{$\begin{array}{l}\text { Sleep } \\
\text { quality }\end{array}$} & Good (>90) & $26(17.3)$ & $9(37.5)$ & $17(13.5)$ & \multirow{3}{*}{0.014} \\
\hline & Fair (70-90) & $72(48.0)$ & $10(41.7)$ & $62(49.2)$ & \\
\hline & Poor $(<70)$ & $52(34.7)$ & $5(20.8)$ & $47(37.3)$ & \\
\hline ESS & $\begin{array}{l}\text { Mean } \pm \text { SD } \\
\text { Min }- \text { Max }\end{array}$ & $\begin{array}{l}10.9 \pm 4.4 \\
3-22\end{array}$ & $9.5 \pm 4.2$ & $12.7 \pm 5.5$ & 0.007 \\
\hline $\begin{array}{c}\text { Arousal } \\
\text { index }\end{array}$ & $\begin{array}{l}\text { Mean } \pm \text { SD } \\
\text { Min }- \text { Max }\end{array}$ & $\begin{array}{c}17.8 \pm 13.2 \\
4-73.4\end{array}$ & $12.7 \pm 10.7$ & $18.6 \pm 12.1$ & 0.027 \\
\hline AHI & $\begin{array}{l}\text { Mean } \pm \text { SD } \\
\text { Min - Max }\end{array}$ & $\begin{array}{l}30.4 \pm 25.0 \\
0-104\end{array}$ & $3.8 \pm 6.3$ & $32.5 \pm 24.4$ & $<0.001$ \\
\hline
\end{tabular}

ESS: Epworth sleepiness score, AHI: apnoea-hypopnea index.

Values present as number \& \% were analyzed by chi-square test.

Values present as mean \pm SD were analyzed by Mann-Whitney U test. 
Regarding laboratory findings, Nadir $\mathrm{SaO} 2$ and maximum $\mathrm{O} 2$ saturation were significantly lower and $\mathrm{PaCO} 2$ was significantly higher among patients with OSA (Table 3).

Table (3): Laboratory findings of the studied sample

\begin{tabular}{|c|c|c|c|c|c|}
\hline \multicolumn{2}{|c|}{ Variables ${ }^{\text {Cases }}$} & $\begin{array}{l}\text { All cases } \\
\mathrm{n}=150(\%)\end{array}$ & $\begin{array}{c}\text { Without } \\
\text { OSA } \\
\text { n=24 }(\%)\end{array}$ & $\begin{array}{c}\text { With OSA } \\
\mathrm{n}=126(\%)\end{array}$ & P-value \\
\hline CRP & $\begin{array}{l}\text { Mean } \pm \text { SD } \\
\text { Min }- \text { Max }\end{array}$ & $\begin{array}{l}2.4 \pm 1.8 \\
0.1-6.0\end{array}$ & $1.84 \pm 2.06$ & $2.58 \pm 1.9$ & 0.087 \\
\hline CPAP & $\begin{array}{l}\text { Mean } \pm \text { SD } \\
\text { Min }- \text { Max }\end{array}$ & $\begin{array}{c}8.0 \pm 4.8 \\
4-20\end{array}$ & $7.8 \pm 4.2$ & $9.5 \pm 4.7$ & 0.101 \\
\hline BIPAP & $\begin{array}{l}\text { Mean } \pm \text { SD } \\
\text { Min }- \text { Max }\end{array}$ & $\begin{array}{c}14.5 \pm 4.3 / 7.4 \pm 2.8 \\
10-19 / 5-11 \\
\end{array}$ & $\begin{array}{l}16.5 \pm 3.9 \\
17.6 \pm 2.9\end{array}$ & $\begin{array}{l}14.9 \pm 4.6 \\
/ 7.9 \pm 3.1\end{array}$ & $\begin{array}{l}0.112 / \\
0.382 \\
\end{array}$ \\
\hline $\begin{array}{c}\text { Max } \\
\mathrm{O}_{2} \text { sat } \\
\end{array}$ & $\begin{array}{l}\text { Mean } \pm \text { SD } \\
\text { Min }- \text { Max }\end{array}$ & $\begin{array}{c}95.1 \pm 5.8 \\
82-99\end{array}$ & $96.5 \pm 6.7$ & $93.5 \pm 6.1$ & 0.031 \\
\hline $\begin{array}{l}\text { Nadir } \\
\mathrm{SaO2}\end{array}$ & $\begin{array}{l}\text { Mean } \pm \text { SD } \\
\text { Min }- \text { Max }\end{array}$ & $\begin{array}{c}82.0 \pm 10.3 \\
30-95\end{array}$ & $89.5 \pm 10.3$ & $81.6 \pm 11.6$ & 0.002 \\
\hline $\mathrm{PaCO}_{2}$ & $\begin{array}{l}\text { Mean } \pm \text { SD } \\
\text { Min }- \text { Max }\end{array}$ & $\begin{array}{c}45.0 \pm 8.1 \\
35-60\end{array}$ & $39.8 \pm 9.4$ & $46.2 \pm 8.1$ & 0.001 \\
\hline
\end{tabular}

CPAP: Continuous positive airway pressure, BiPAP: Bi-level positive airway pressure.

Values present as mean \pm SD were analyzed by Mann-Whitney $U$ test.

Variables that showed significant differences in previous tables were further evaluated according to degree of severity of OSA. Increasing age, BMI, ESS, arousal index, $\mathrm{AHI}, \mathrm{PaCO} 2$ and presence of HTN or DM was found to be significantly associated with increased severity of OSA. Decreasing sleep efficiency or Nadir SaO2 was found to be significantly associated with increased severity of OSA. However, no significant differences in the degree of severity of OSA were found regarding gender, sleep quality or maximum $\mathrm{O} 2$ saturation (Table 4). 
Table (4): Relation between severity of obstructive sleep apnea and different study variables

\begin{tabular}{|c|c|c|c|c|c|c|}
\hline \multicolumn{2}{|c|}{$\begin{array}{ll}\text { Variables } & \text { Cases } \\
\end{array}$} & $\begin{array}{c}\text { Normal } \\
\mathrm{n}=24(\%)\end{array}$ & $\begin{array}{c}\text { Mild } \\
\mathrm{n}=24(\%)\end{array}$ & $\begin{array}{c}\text { Moderate } \\
\mathrm{n}=45(\%)\end{array}$ & $\begin{array}{c}\text { Severe } \\
\mathrm{n}=57(\%)\end{array}$ & P-value \\
\hline \multicolumn{2}{|c|}{ Age (years) } & $48.4 \pm 13.6$ & $50.6 \pm 12.8$ & $53.2 \pm 9.2$ & $56.3 \pm 10.6$ & 0.019 \\
\hline \multirow{2}{*}{ Gender } & Male & $9(37.5)$ & $13(54.2)$ & $25(55.6)$ & $37(64.9)$ & \multirow{2}{*}{0.157} \\
\hline & Female & $15(62.5)$ & $11(45.8)$ & $20(44.4)$ & $20(35.1)$ & \\
\hline \multicolumn{2}{|c|}{ BMI } & $33.9 \pm 8.2$ & $35.1 \pm 7.0$ & $38.5 \pm 8.8$ & $41.2 \pm 6.9$ & $<0.001$ \\
\hline \multicolumn{2}{|c|}{ HTN } & $8(33.3)$ & $12(50.0)$ & $22(48.9)$ & $40(70.1)$ & 0.013 \\
\hline \multicolumn{2}{|c|}{ DM } & $5(20.8)$ & $8(33.3)$ & $16(35.6)$ & $30(52.6)$ & 040 \\
\hline \multicolumn{2}{|c|}{ Sleep efficiency } & $77.8 \pm 17.7$ & $75.1 \pm 15.2$ & $69.2 \pm 16.1$ & $68.0 \pm 15.0$ & .037 \\
\hline \multirow{3}{*}{$\begin{array}{c}\text { Sleep } \\
\text { Quality }\end{array}$} & Good $(>90)$ & $9(37.5)$ & $5(20.8)$ & $6(13.3)$ & $6(10.5)$ & \multirow{3}{*}{0.075} \\
\hline & Fair (70-90) & $10(41.7)$ & $11(45.8)$ & $25(55.6)$ & $26(45.6)$ & \\
\hline & Poor $(<70)$ & $5(20.8)$ & $8(33.3)$ & $14(31.1)$ & $25(43.9)$ & \\
\hline \multicolumn{2}{|c|}{ ESS } & $9.5 \pm 4.2$ & $10.4 \pm 4.1$ & $12.0 \pm 5.6$ & $13.5 \pm 5.4$ & 0.006 \\
\hline \multicolumn{2}{|c|}{ Arousal index } & $12.7 \pm 10.7$ & $14.8 \pm 10.6$ & $17.8 \pm 11.6$ & $22.6 \pm 12.2$ & 0.002 \\
\hline \multicolumn{2}{|c|}{ AHI } & $3.8 \pm 6.3$ & $11.5 \pm 7.7$ & $22.8 \pm 12.4$ & $48.5 \pm 20.1$ & $<0.001$ \\
\hline \multicolumn{2}{|c|}{ Max $\mathrm{O}_{2}$ sat } & $96.5 \pm 6.7$ & $95.2 \pm 5.8$ & $94.5 \pm 6.6$ & $92.8 \pm 7.4$ & 0.132 \\
\hline \multicolumn{2}{|c|}{ Nadir $\mathrm{SaO2}$} & $89.5 \pm 10.3$ & $86.3 \pm 11.4$ & $81.9 \pm 10.8$ & $75.5 \pm 11.2$ & $<0.001$ \\
\hline \multicolumn{2}{|c|}{$\mathrm{PaCO}_{2}$} & $39.8 \pm 9.4$ & $42.6 \pm 7.8$ & $47.1 \pm 8.9$ & $48.8 \pm 8.3$ & $<0.001$ \\
\hline
\end{tabular}

Values present as number \& \% were analyzed by chi-square test.

Values present as mean \pm SD were analyzed by Kruskal-Wallis test.

Further evaluation showed that the severity of OSA had significant positive correlation with BMI ( $\rho=0.13, \mathrm{P}=0.005)$ and significant negative correlation with Nadir SaO2 $(\rho=0.27, \mathrm{P}=0.001)$. BMI had significant negative correlation with Nadir $\mathrm{SaO} 2(\rho=-0.18, \mathrm{P}=0.027)$. We assessed the diagnostic ability of different cut-offs of Nadir $\mathrm{SaO} 2$ and BMI for the prediction of OSA using ROC curve that maximizes both sensitivity and specificity. For Nadir $\mathrm{SaO} 2, \mathrm{AUC}=0.86$ (95\% CI $0.80-0.92$, $\mathrm{P}<0.001)$ with optimal cut-off was 74.5 , sensitivity $=78 \%$, specificity $=79 \%$, and for BMI, AUC $=0.86$ (95\% CI $0.76-0.95$, $\mathrm{P}<0.001)$ with optimal cut-off was 33.9, sensitivity $=81 \%$, specificity $=75 \%$ (Figure 1).

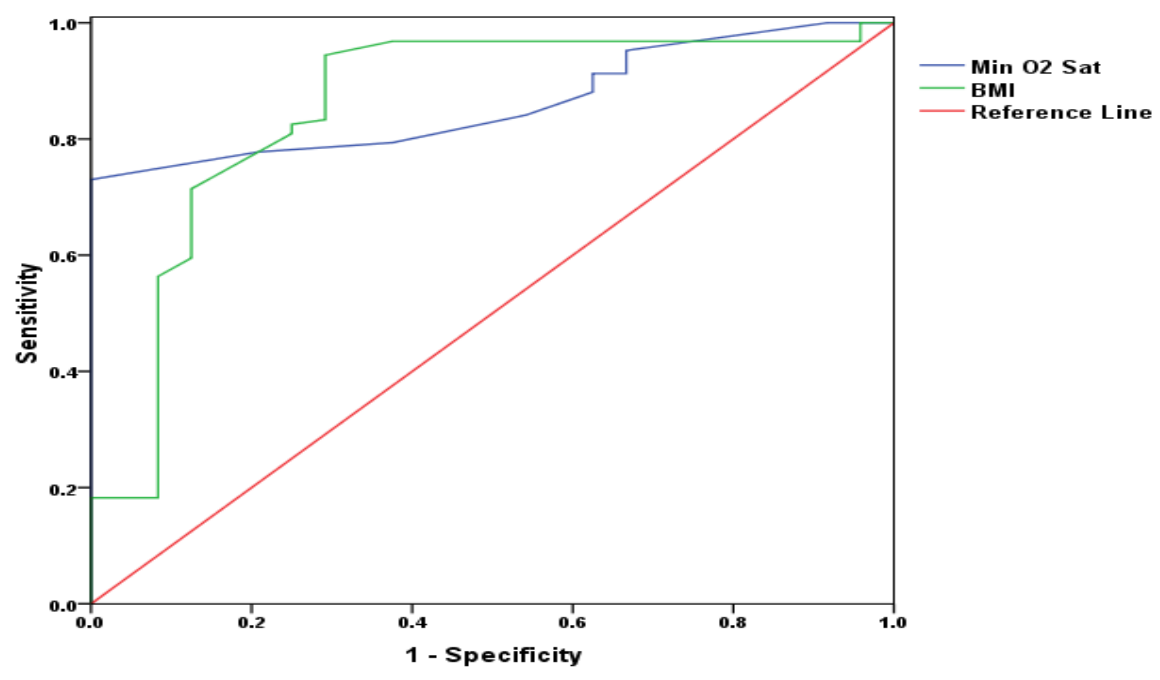

Figure (1): ROC curve analysis of Nadir $\mathrm{SaO} 2$ (minimum $\mathrm{O} 2$ saturation) and BMI 


\section{DISCUSSION}

In the present study, male sex $(56 \%)$ was associated with a higher risk of having OSA and increased risk of severity of the disease. Consistent reporting of higher OSA prevalence in men and association of OSA with male sex was found in the literature Yuceege et al. (2014) and Wickramasinghe (2020) observed that the male-to-female ratio for the prevalence of sleep-disordered breathing (SDB) in the general population is approximately $2-3: 1$, and the male-tofemale ratio for patients referred to sleep clinics for an evaluation of possible OSA is approximately 10:1. OSA appears to be notably underdiagnosed in females and a high index of suspicion must be maintained when screening females for SDB.

Wali and his Colleagues (2017) studied subjects by polysomnography and confirmed the findings of previous epidemiological studies regarding this male predominance, with this condition occurring in $70.2 \%$ of males versus $29.8 \%$ of females. This male predominance may be related to several factors, including hormonal effects in the muscles of the upper airways, gender-based differences in the distribution of adipose tissue, variances in pharyngeal shape, size, and collapsibility, and differences in ventilation control (Kapsimalis et al., 2012). This finding raises the possibility that OSA is underestimated in females simply because they have a more diverse clinical presentation of OSA than males. Furthermore, a recent study among the Swedish population reported a high prevalence of OSA among females (Franklin et al., 2013).
We observed that the mean age of patients with OSA was significantly higher than non-OSA patients and the severity of OSA increase with increase of the age Esmaeel and his colleagues (2019) found that the mean age of patients with OSA was significantly higher than nonOSA patients. Higher age showed 1.07fold increased risk of having OSA .In agreement with our results, Martins and his Colleagues (2017) proved that age is an independent risk factor for OSA with the assumption that this can be explained by the age-related reduction in muscle tone that results in decrease diameters of upper airway lumen. In contrary to our results, Leppänen and his Colleagues (2019) found that age was not statistically significantly different between the OSA severity categories.

In the present study the means of Epworth sleepiness score (ESS) was significantly higher among patients with OSA. SDB was most frequently assessed by a sleep physician using the ESS. This questionnaire was used to help determine how frequently the patient is likely to doze off in 8 frequently encountered situations. Although patients do not always accurately describe their sleepiness on this scale compared with objective measures, an ESS score greater than 10 is generally considered sleepy (Punjabi et al., 2011).

The ESS score does not correlate well with the primary objective measurement of sleepiness, the MSLT in that a higher ESS score does not mean shorter latencies on (Benbadis et al., 2010 and Chervin and Aldrich, 2010) the MSLT. However, a higher ESS score does mean a greater likelihood of falling asleep on the MSLT 
(Punjabi et al., 2011). The ESS is useful for evaluating responses to treatment; the ESS score should decrease with effective treatment (Black and Hirshkowitz, 2015).

The majority $(84 \%)$ of patients included in this study were diagnosed with OSA. These findings were in agreement with Alshehri and his colleagues (2019) who found that $74.8 \%$ of patients included in their study, were diagnosed with OSA. Furthermore, their study showed that males had a significantly higher prevalence of OSA and mean AHI than females. This can be associated with the higher prevalence of both obesity and snoring in males.

Gharib and Loza. (2020) found that $83 \%$ of the patients referred to their sleep center were diagnosed with OSA.

Wali and his Colleagues (2017) found that $67.9 \%$ had OSA. However, the multiple logistic regression analysis only identified the male gender, age $\geq 50$ years, obesity as defined by a BMI $\geq 30 \mathrm{~kg} / \mathrm{m} 2$, and a history of hypertension as significant risk factors associated with OSA.

The most relevant finding of this study was that most of our patients were obese and the mean BMI was significantly higher in OSA than non-OSA participants. Approximately, $30 \%$ of patients with a BMI greater than 30 and $50 \%$ of those with a BMI greater than 40 have OSA. Unfortunately, obesity has become an epidemic in industrialized nations (Wickramasinghe, 2020).

Increasing BMI found to be significantly associated with increased severity of OSA. This finding was in accordance with many studies in the literature that documented the association between higher BMI and increased risk of OSA (Reddy et al., 2010 and (Hiestand et al., 2016). Wali et al.(2017) observed that obesityas assessed by BMI but no other biometric data was significantly increased in OSA patients compared with non-OSA patients .Similarly, Leppänen et al. (2019) found that BMI increased statistically significantly towards more-severe OSA categories, and the severity of individual obstruction events were strongly associated with BMI. In more-detailed analysis, values of AHI, oxygen desaturation index (ODI), and hypopnea index increased statistically significantly.

In addition, these findings suggested a positive correlation between obesity and the severity of OSA, as subjects with higher BMI scored higher AHI values on the polysomnographic test. This result was expected as obesity is widely considered a risk factor for OSA and is thought to increase the severity of the syndrome. This effect of obesity on the severity of OSA may be caused by alterations in the normal airway functioning owing to excessive fat accumulation around the pharynx, leading to a reduction of the size of the airway passage (Alshehri et al. (2019).

In contrary to our findings, Ciavarella et al., (2018) did polysomnography on seventy-five adult patients (mean age 51.4 years), and found no correlation between BMI and AHI. However, they reported a statistically significant negative correlation between the BMI index and the Nadir $\mathrm{SaO} 2$ ) that was consistent with our results.

Ogretmenoglu et al., (2015) have suggested that the BMI together with body 
fat correlate more closely with the AHI. Contrasting with most published papers, these authors believe that neck circumference (NC) correlates poorly with the OSAHS., Katz et al. (2010) found that the BMI, age, the internal laryngeal circumference and $\mathrm{NC}$ were significant predictors of OSAHS, and they argued that the $\mathrm{NC}$ is the most important measurement as a parameter for OSAHS.

In the present study, the desaturation depth increased significantly with increasing BMI in the mild and moderate OSA categories. Sato et al., (2011) found that the depth and area of desaturation events increased statistically significantly with increasing BMI only in the severe OSA category. This can also be seen in the obstruction severity parameter, which increased statistically significantly with increasing BMI only in subjects with severe OSA due to greater hypoxemia .On the other hand, Leppanen et al., (2019) found the desaturation depth did not change statistically significantly with increasing BMI in the mild and moderate OSA categories, albeit increasing trend towards higher BMI was observed in the BMI group level.

Regarding comorbidities, hypertension and diabetes mellitus were found to be more prevalent in the OSA group than in non-OSA group and in particular in the severe OSA subgroup and the difference was statistically significant. There is accumulating evidence in the literature about the association between OSA both hypertension and diabetes mellitus. Some researchers reached to a conclusion in their review about this patient that sleep duration and quality are linked to the glycemic control in patients with type 2 diabetes (Tkacova et al., 2014 and Sweed et al., 2019).

OSA was confirmed in our study group by PSG, which adds reliability to our study results. Many published studies assessed the risk factors of OSA, while utilizing validated simple questionnaires only without performing PSG. Also, presence of a control group (non-OSA) for comparisons was another strength.

One of the study limitations was that it was conducted at a single, large, tertiary hospital with relatively small number of our cases. Second, prevalence of obesity in Saudi Arabia is known to be high, and accordingly, generalization of results to other ethnic groups may not be appropriate. Third, selection bias, as our patients' chief complaint was snoring as witnessed by a sleep partner with high probability of disease, not a representative sample of the general adult population. Finally, we cannot exclude the possibility of residual confounding by unmeasured factors such as socioeconomic status, family history of sleep apnea, smoking and asthma.

\section{CONCLUSION}

Higher BMI values were correlated with lower Nadir $\mathrm{SaO} 2$ during overnight polysomnography. Since hypoxia stress is a risk factor for cardiovascular diseases and alters the lipid metabolism, dietary consulting should be recommended in association with other treatment modalities for OSA.

\section{REFERENCES}

1. Alshehri KA, Bashamakh LF, Alshamrani HM, Alghamdi IO, Mahin BA and Alharbi AA.(2019): (Pattern and severity of sleep apnea in a Saudi sleep center: The impact of 
obesity. J Fam Community Med), 26:127132.

2. American Academy of Sleep Medicine Task Force (2010): Sleep-related breathing disorders in adults, recommendations for syndrome definition and measurement techniques in clinical research. Sleep, 22:667-689.

3. Benbadis SR, Mascha E, Perry MC, Wolgamuth BR, Smolley LA and Dinner DS. (2010): Association between the Epworth sleepiness scale and the multiple sleep latency test in a clinical population. Ann Intern Med) 130(4 Pt 1):289-292.

4. Black JE and Hirshkowitz M. (2015): Modafinil for treatment of residual excessive sleepiness in nasal continuous positive airway pressure-treated obstructive sleep apnea/hypopnea syndrome. Sleep, 28(4):464471.

5. Caples SM, Gami AS and Somers VK. (2015): Obstructive sleep apnea. Ann Intern Med. 142:187-197.

6. Chervin RD and Aldrich MS (2010): The Epworth Sleepiness Scale may not reflect objective measures of sleepiness or sleep apnea. Neurology,52(1):125-131.

7. Chung F, Yang $Y$ and Liao $P$ (2013): Predictive performance of the STOP-Bang scores for identifying obstructive sleep apnea in obese patients. ObesSurg 23:2050-2057.

8. Ciavarella D, TepedinoM, ChimentiC, TroianoG, Mazzotta M and Barbaro MP (2018): Correlation between body mass index and obstructive sleep apnea severity indexes A retrospective study. Am J Otolaryngol39 (4):388-391.

9. Durán J, Esnaola S, Ramón $\mathbf{R}$ and Iztueta A (2010): Obstructive sleep apnea-hypopnea and related clinical features in a populationbased sample of subjects aged 30 to 70 years. Am J Respir Crit Care Med 163:685-689.

10. Esmaeel HM, Mohammadien HA, Saleh AM and Mohamed FH. (2019): Prepolysomnography evaluation can predict obstructive sleep apnea and is correlated to its severity. Egypt J Bronchol13:556-562.
11. Franklin KA, Sahlin $C$, Stenlund $H$ and Lindberg E (2013): Sleep apnoea is a common occurrence in females. Eur Respir J41:610-615.

12. Gharib A and Loza S. (2020): Factors affecting the severity of the apnea hypoapnea index: a retrospective study on 838 Egyptian patients diagnosed with obstructive sleep apnea. Egypt J Bronchol 14 - 34.

13. Hiestand DM, Britz P, Goldman $M$ and Phillips B (2016): Prevalence of symptoms and risk of sleep apnea in the US population: results from the national sleep foundation sleep in America 2005 poll. Chest 130:780786.

14. Iber $\mathrm{C}$, Ancoli-Israel S, Chesson $\mathrm{AL}$ and Quan SF (2017): The AASM Manual for the scoring of sleep and associated events: rules, terminology and technical specifications. Westchester, IL: American Academy of Sleep Medicine.

15. Kapsimalis F and Kryger MH (2012): Gender and obstructive sleep apnea syndrome, Part 2: Mechanisms. Sleep 25:499-506.

16. Katz I, Stradling J, Slutsky AS, Zamel N and Hoffstein V (2010): Do patients with obstructive sleep apnea have thick necks? Am Rev Respir Dis 141(5 Pt 1):1228-1231.

17. Kim SE, Park BS, Park SH, Shin KJ, Ha SY and Park JS. (2015): Predictors for Presence and Severity of Obstructive Sleep Apnea in Snoring Patients: Significance of Neck Circumference. J Sleep Med 12(2):3438.

18. Leppanen T, Kulka A T, Mervaala $\mathbf{E}$ and Juha T (2019): Increase in Body Mass Index Decreases Duration of Apneas and Hypopneas in Obstructive Sleep Apnea. Respir Care 64(1):77-84.

19. Loberes P, Durán-Cantolla J, MartínezGarcía MA, Marín JM, Ferrer $A$ and Corral J (2011): Diagnóstico y tratamiento del síndrome de apneas-hipopneas del sueno. Arch Bronconeumol47:143-156.

20. Mannarino MR, Di Filippo $\mathbf{F}$ and Pirro $M$ (2012): Obstructive sleep apnea syndrome. Eur J Intern Med 23(7):586-593. 
21. Martins AB, Tufik $S$ and Moura SM (2017): Physiopathology of obstructive sleep apnea-hypopnea syndrome. J Bras Pneumol33:93-100.

22. Ogretmenoglu O, Suslu AE, Yücel OT, Onerci TM and Sahin A (2015): Body fat composition: a predictive factor for obstructive sleep apnea. Laryngoscope, 115:1493-1498.

23. Punjabi NM, Bandeen-Roche $K$ and Young T (2013): Predictors of objective sleep tendency in the general population. Sleep, 26(6):678-683.

24. Punjabi NM, O'hearn DJ, Neubauer DN, Nieto FJ, Schwartz AR and Smith PL (2011): Modeling hypersomnolence in sleepdisordered breathing. A novel approach using survival analysis. Am J Respir Crit Care Med159 (6):1703-1709.

25. Reddy EV, Kadhiravan T, Mishra HK, Sreenivas V, Handa KK and Sinha $S$ (2010): Prevalence and risk factors of obstructive sleep apnea among middle-aged urban Indians: a community-based study. Sleep Med 10:913-918.

26. Ruehland WR, Rochford PD, O'Donoghue FJ, Pierce RJ, Singh $P$ and Thornton AT (2011): The new AASM criteria for scoring hypopneas: impact on the apnea hypopnea index. Sleep, 32:150-157.

27. Sakakibara H, Tong M, Matsushita K, Hirata M, Konishi $Y$ and Suetsugu $S$ (2010): Cephalometric abnormalities in nonobese and obese patients with obstructive sleep apnoea. Eur Respir J., 13:403-410.

28. Sato M, Suzuki M, Suzuki J, Endo Y, Chiba $Y$ and Matsuura $M$ (2011): Overweight patients with severe sleep apnea experience deeper oxygen desaturation at apneic events. J Med Dent Sci., 55(1):43- 47.
29. Sweed RA, Hassan S, Abd EIWahab NH, Aref SR and Mahmoud MI (2019): Comorbidities associated with obstructive sleep apnea: a retrospective Egyptian study on 244 patients. Sleep Breath, 23(4):10791085 .

30. Tishler PV, Larkin EK, Schluchter MD and Redline S (2013): Incidence of sleep disordered breathing in an urban adult population: the relative importance of risk factors in the development of sleepdisordered breathing. JAMA 289:2230-2237.

31. Tkacova R, McNicholas WT, Javorsky M, Fietze I, Sliwinski P and Parati G (2014): Nocturnal intermittent hypoxia predicts prevalent hypertension in the European sleep Apnoea database cohort study. Eur Respir J, 44(4):931-941.

32. Vgontzas AN. (2018): Does obesity play a major role in the pathogenesis of sleep apnoea and its associated manifestations via inflammation, visceral adiposity, and insulin resistance? Arch Physiol Biochem, 114:211223.

33. Wali SO, AbalkhailB and Krayem A (2017): Prevalence and risk factors of obstructive sleep apnea syndrome in a Saudi Arabian population. Ann Thorac Med 12(2):88-94.

34. Wolk R, Shamsuzzaman AS and Somers VK (2013): Obesity, Sleep Apnea, and Hypertension. Hypertension 42:1067-1074.

35. Young T, Palta M, Dempsey J, Skatrud J, Weber $S$ and Badr $S$ (2013): The occurrence of sleep-disordered breathing among middle-aged adults. N Engl J Med 328:1230-1235.

36. Yuceege M, Firat $H$, Ardic $S$ and Demir A (2014): Gender difference in apnea and hypopnea component in obstructive sleep apnea. J Turkish Sleep Med 1:16-21. 
مؤشر كتلة الجسم باعتبار هؤشر ا لانقطاع النفس الانسدادي

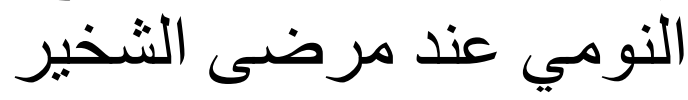

خالد محمد حليمه1، صفوت محمد أحمد الدعبوسى1، أمجد عوض2، صابرأبوالحسن3، محمد أسامة نور 4

قسم الأمراض الصدرية, كلية الطب, جامعة الأزهر بالقاهرة ،جمهورية مصر العربية، قسم الأمراض

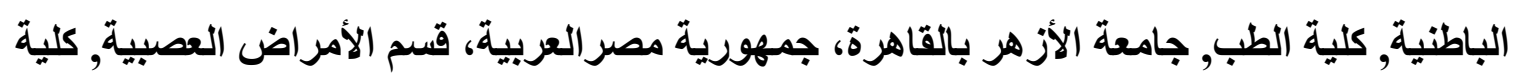

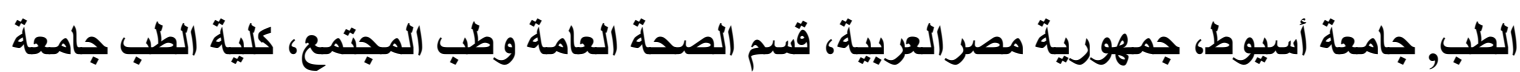
الأزهر بدمياط، جمهورية مصر العربية

E-mail: khaledchesthalima@gmail.com

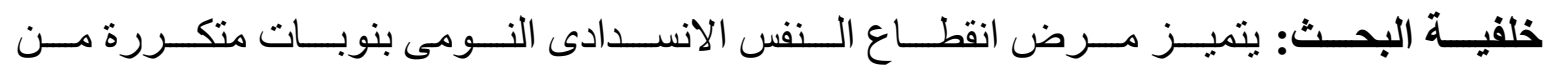

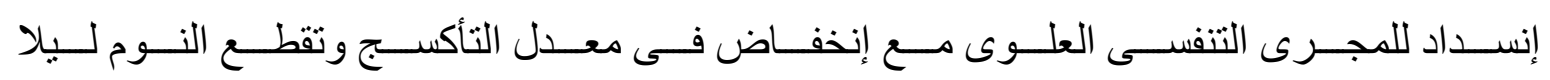
مع النعاس الزائد خلال النهار.

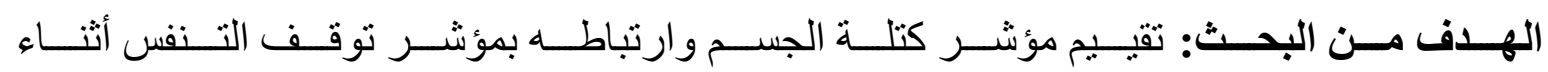

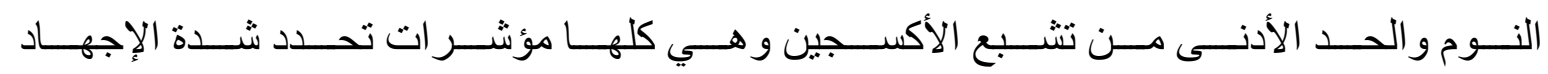
التنفسي المرتبط بانقطاع النفس الانسدادي النومي.

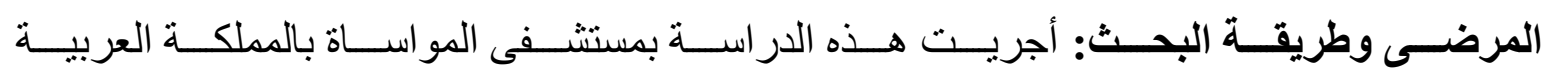

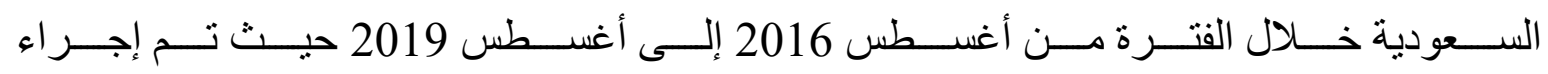

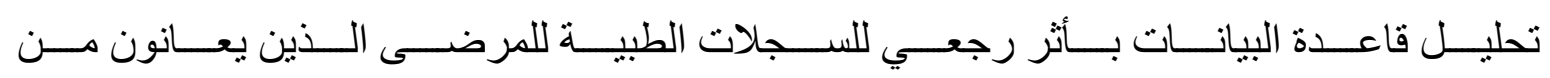

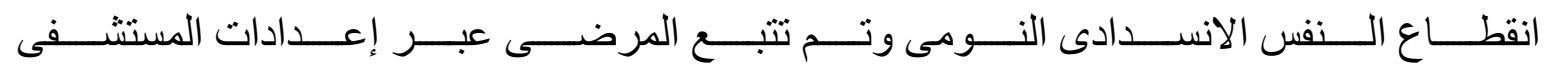

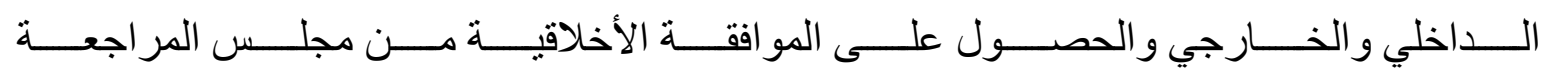

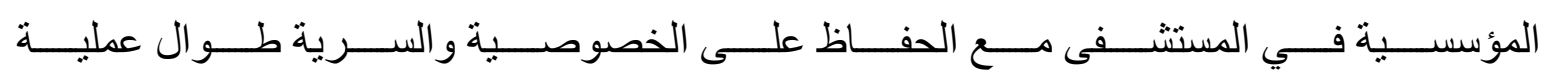

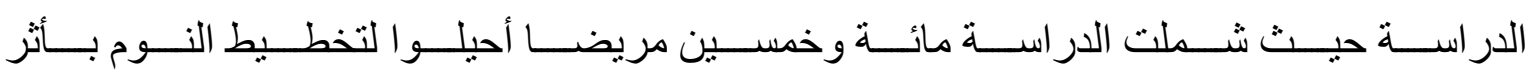

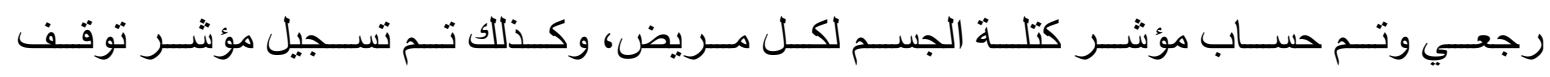

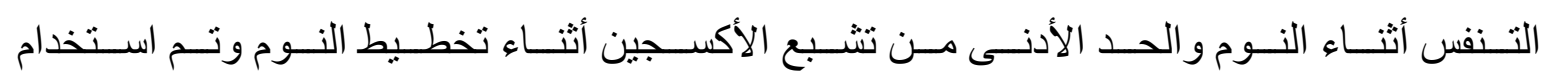

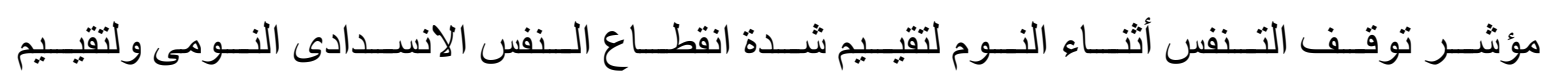
ما إذا كان هناك ارنباط بقيم مؤشر كتلة الجسم. 


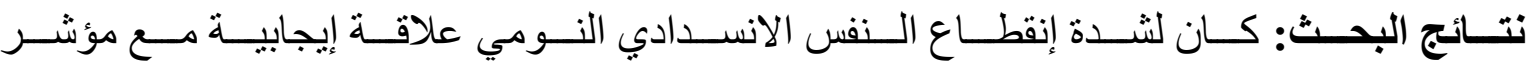
كتلة الجسموارتباط سلبي مع الحد الأدنى من التشبع بالأكسجين.

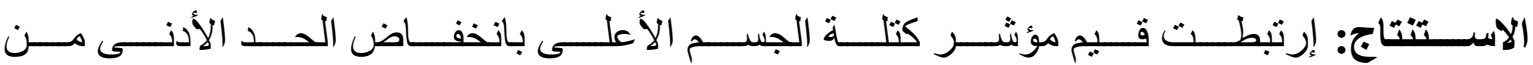
النتبع بالأكسجين أثناء تخطيط النوم الليلي.

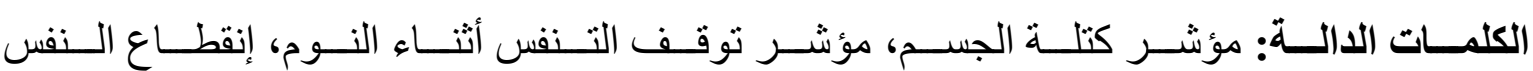
الانسدادى النومى، الحد الأدنى من تثبع الأكسجين. 